\title{
Article \\ Deformation Characteristics of Soil Layers and Diaphragm Walls during Deep Foundation Pit Excavation: Simulation Verification and Parameter Analysis
}

\author{
Zheyuan Feng ${ }^{1}$, Qi Xu ${ }^{1}$, Xiangyang $X u^{1, *}$, Qiang Tang ${ }^{1, *}$, Xuedong $\mathrm{Li}^{2,3}$ and Xin Liao ${ }^{4,5}$ \\ 1 School of Rail Transportation, Soochow University, Suzhou 215131, China; fengzheyuan1999@sina.com (Z.F.); \\ szwzxq@outlook.com (Q.X.) \\ 2 Jiangsu Suzhou Geological Engineering Survey Institute, Suzhou 215011, China; \\ lixlixuedong12@outlook.com \\ 3 The Fourth Geological Brigade of Jiangsu Geological and Mineral Bureau, Suzhou 215004, China \\ 4 Faculty of Geosciences and Environmental Engineering, Southwest Jiaotong University, \\ Chengdu 611756, China; xinliao@swjtu.edu.cn \\ 5 MOE Key Laboratory of High-Speed Railway Engineering, Southwest Jiaotong University, \\ Chengdu 611756, China \\ * Correspondence: x.y.xu@suda.edu.cn (X.X.); tangqiang@suda.edu.cn (Q.T.)
}

check for updates

Citation: Feng, Z.; Xu, Q.; Xu, X.;

Tang, Q.; Li, X.; Liao, X. Deformation Characteristics of Soil Layers and Diaphragm Walls during Deep Foundation Pit Excavation: Simulation Verification and Parameter Analysis. Symmetry 2022 14, 254. https://doi.org/10.3390/ sym 14020254

Academic Editor: Raffaele Barretta

Received: 3 January 2022

Accepted: 19 January 2022

Published: 28 January 2022

Publisher's Note: MDPI stays neutral with regard to jurisdictional claims in published maps and institutional affiliations.

Copyright: (C) 2022 by the authors. Licensee MDPI, Basel, Switzerland. This article is an open access article distributed under the terms and conditions of the Creative Commons Attribution (CC BY) license (https:// creativecommons.org/licenses/by/ $4.0 /)$.

\begin{abstract}
The research on the deformation of soil mass and ground connection walls is not sufficiently thorough due to the huge risk of deep excavation in soft soil areas. In this paper, finite element software is used to numerically simulate a symmetrical foundation pit in Suzhou, and the reliability is verified by on-site measured data. The purpose of this study is to investigate the deformation mechanism of the enclosure structure and surrounding soil during the excavation of soft soil foundation pits, and to carry out sensitivity analysis. The results show that the maximum subsidence of the surface is $21.25 \mathrm{~mm}$, the maximum horizontal displacement of the underground diaphragm wall is $9.45 \mathrm{~mm}$, and the maximum uplift of the pit bottom is $21.46 \mathrm{~mm}$. By changing the soil layer properties (the elastic modulus, cohesion, and internal friction angle) and the insertion ratio of the diaphragm wall, the maximum horizontal displacement of the diaphragm wall is more easily affected than the maximum settlement of the surface. Based on different research results, the maximum land subsidence and maximum horizontal displacement of the support structure are $0.313-0.060 \%$ and $0.070-0.250 \%$ of the maximum excavation depth, respectively. Finally, the simulation may have some applicability to other foundation pit excavations.
\end{abstract}

Keywords: numerical analysis; ground settlement; supporting structure displacement; sensitivity analysis

\section{Introduction}

With the continuous advancement of the world's urbanization process, the development and utilization of aboveground space is gradually becoming saturated, which is causing a global speeding up of the development of underground space-this is gradually becoming an important way to solve urban contradictions [1-3]. The construction of underground space plays a big part in the process of large-scale urban development. While improving the ground environment, it provides sufficient space for urban construction [4-6]. In view of the environmental pollution, resource shortage, traffic congestion, and high housing prices that constantly appear in the process of urban development, utilizing underground space has become one of the best choices to promote the process of urbanization [7-10].

The development and utilization of underground space will inevitably encounter soft soil zones, with high groundwater levels and low soil strength [11]. The excavation of deep foundation pits and the constraints of soft soil engineering geological conditions 
have become increasingly prominent contradictions [12-14]. Moreover, plenty of high-rise buildings, underground shopping malls, subways, etc. are built in densely constructed areas in cities [15]. These areas have stricter requirements with regard to deformation and improper engineering actions that cause imbalances in the rock and soil environment, such as deep foundation pits [16-19]. Excavation causes ground settlement and cracks around the site, as well as having an impact on built structures [20]. Therefore, the design of pit excavation has become a hot spot in geotechnical engineering.

The excavation of a pit usually results in surface deformation, increasing the potential threat to the surrounding environment [17]. Reducing the surface deformation so as to protect the surrounding environment has been widely discussed. In the engineering design stage, the selection and design of the supporting structure should not only consider the stability of pits, but also pay attention to reducing the surface deformation near the pit [18-21]. Only in the excavation stage can the surrounding buildings be protected from damage [22]. At present, research throughout the world is mainly focused on ground settlement around foundation pits in order to determine whether foundation pit excavation will cause damage to these surroundings, especially uneven settlement within the excavation range [23]. This is considered to be the main reason for the damage to buildings that occurs around foundation pits $[18,19]$. To protect adjacent buildings, domestic and foreign scholars have conducted much research on the supporting structures of adjacent buildings' foundation pits [24-26]. Common support structures include bored pile supports, soil mixing wall construction method piles, caissons, and double-row piles [27,28]. To solve the problem of the impact on adjacent buildings, previously established technical research ideas include increasing the rigidity of the supporting structure, increasing the lateral support, and prereinforcing the adjacent buildings [29-31]. Quaternary sedimentary soft soils are widely distributed in the world, and the Suzhou area is a typical representative area of lacustrine soft soils. Lakeside soft soil has the characteristic of low bearing capacity, which leads to the risk of severe surface deformation around the foundation pit. However, the current research on soft soil in this specific area is limited, especially in terms of the lack of research on sensitivity. This paper focuses on how to control the maximum horizontal displacement of the underground diaphragm wall and the maximum settlement around the foundation pit. Therefore, this paper takes the underground diaphragm wall as an example, and finds the best insertion ratio by changing the insertion ratio of the underground diaphragm wall, considering cost control and risk synthesis. In addition, this paper discusses the sensitivity analysis of the insertion ratio of the diaphragm wall to the maximum surface settlement around the foundation pit and the maximum horizontal displacement of the diaphragm wall, so as to provide a reference for the design.

In this paper, by changing the characteristics of the internal friction angle, cohesion, and elastic modulus of the soil layer, the sensitivity to the settlement around the foundation pit and the supporting structure is analyzed. On the basis of summarizing the relationship between the excavation depth and the maximum surface settlement around the foundation pit and the maximum horizontal displacement of the support structure, this paper proposes the maximum settlement around the foundation pit (Smax), the excavation depth $\left(D_{\max }\right)$, and the maximum horizontal displacement of the support structure (the concept of the ratio of $\left.\mathrm{H}_{\max }\right)$ to the excavation depth. By summarizing the general range intervals $\left(\mathrm{S}_{\max } / \mathrm{D}_{\max }\right.$ and $\left.\mathrm{H}_{\max } / \mathrm{D}_{\max }\right)$, this paper contributes a new idea pertaining to the reliability assessment of foundation pit support structures.

\section{Project Profile}

Based on the Suzhou Caohu Tunnel Project, this paper analyzes one of the typical foundation pits, as shown in Figure 1. The length of the tunnel project is $1.26 \mathrm{~km}$, the open section is $390 \mathrm{~m}$ long, and it has an overall U-shaped groove structure. Among them, the buried section is $870 \mathrm{~m}$ long and has a single-box double-chamber structure. According to the stratum revealed by this survey, the foundation soil of the proposed site is mainly 
composed of cohesive soil, sandy silt, and sandy soil. The plan view of foundation pit studied in this paper is shown in Figure 2.

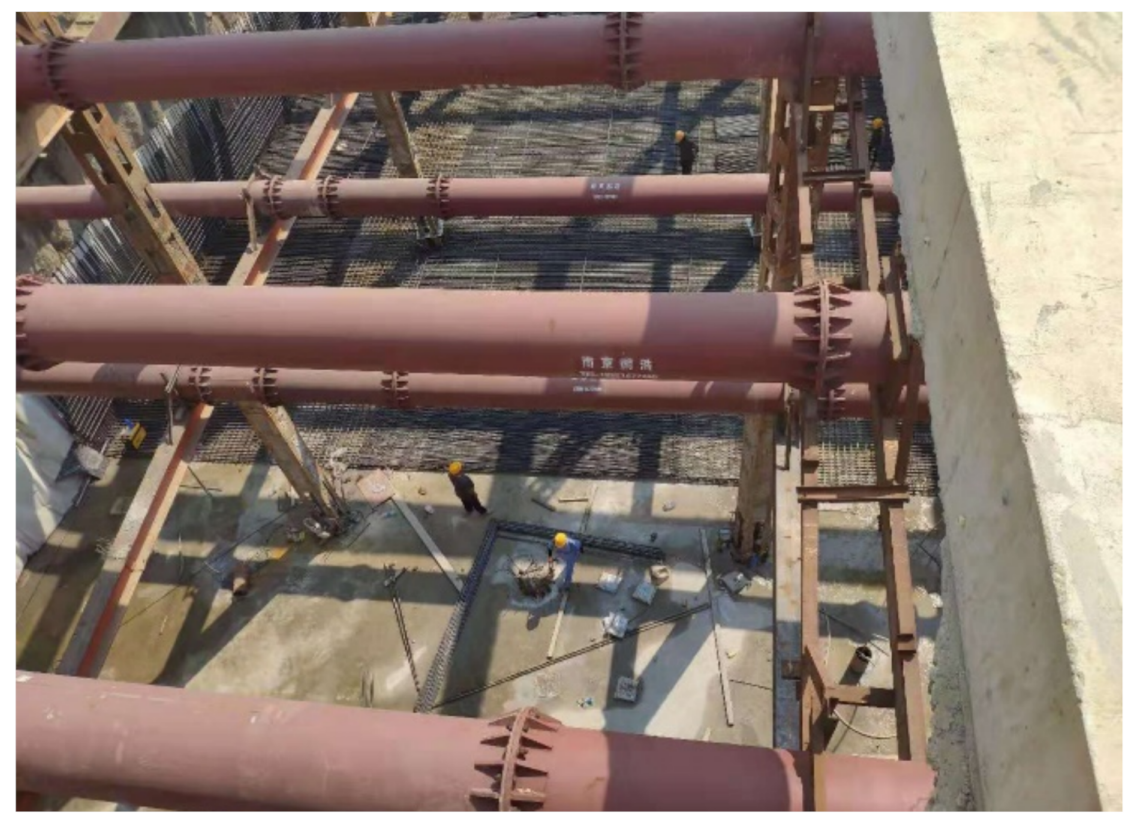

Figure 1. Site photos of the foundation pit.

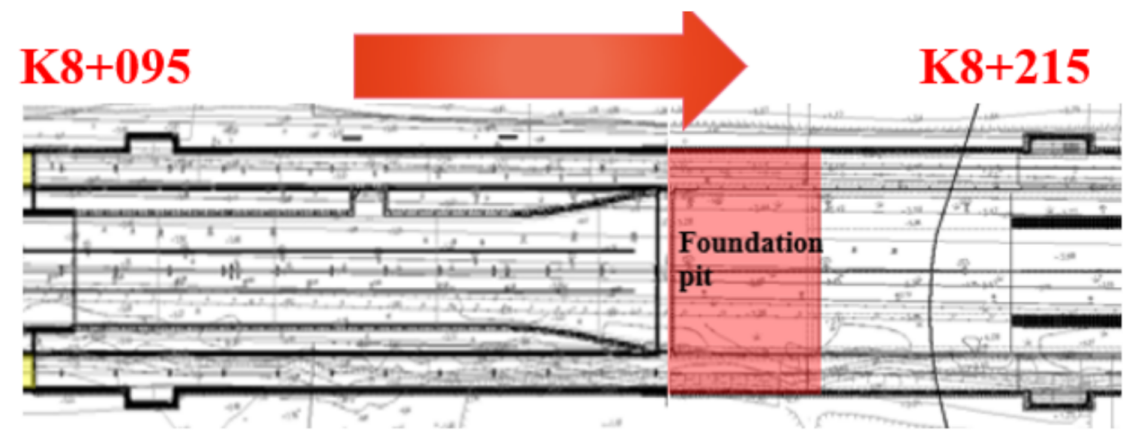

Figure 2. Plan view of the foundation pit.

\section{Numerical Models}

\subsection{Soil Model Selection}

Midas is a kind of finite element analysis software, related to structural design, which was developed by the Midas company of South Korea. It is divided into four categories: the construction field, the bridge field, the geotechnical field, and the simulation field. This article uses Midas GTS NX, which belongs to the geotechnical field. The main material parameters and scope of application of the continuum model of soil commonly used in MIDAS are different. Among them, the Mohr-Coulomb model and the Drucker-Prager model are the most widely used models [32-34]. Because of their simple model parameters, they are easy to determine in the survey report. However, since the elastic modulus is the same as the compression modulus, it is prone to surface uplift and cannot reflect the soil. The plastic properties of soil cannot be reflected by the Duncan-Chang model because it is an elastic model. The deformation characteristics of the field can be better simulated by the modified Cam-Clay model. The modified Mohr-Coulomb model can simulate the double hardening behavior that is not affected by shear failure or compression yield. The unloading elastic modulus can be set to prevent the simulation of soil excavation from producing large surface uplifts. However, the material parameters of the modified CamClay model and modified Mohr-Coulomb model are numerous and difficult to determine, 
and some parameters need to be derived through derivation. Therefore, this paper uses the Mohr-Coulomb model.

\subsection{Basic Assumptions of Calculation}

MIDAS GTS/NX, which simulates the excavation steps of the pit, is used in this paper. The three-dimensional modeling of the pit makes the following assumptions: First of all, the materials are considered to be uniform in the three-dimensional model, the soil layers are uniformly distributed, and the contact surface is horizontal. Then, the impact of groundwater permeability and variation is not considered. Finally, it is assumed that the excavation of the pit and the application of the supporting structure are carried out layer by layer, which indicates that there is no phenomenon of simultaneous multilayer construction.

\subsection{Material Parameter Setting}

The model foundation pit is $22.4 \mathrm{~m}$ wide, $18.0 \mathrm{~m}$ deep, and $50.0 \mathrm{~m}$ long. The cross section with a side length of $800 \mathrm{~mm}$ is square reinforced concrete, which is used as the first support, and the distance between concrete supports is $6 \mathrm{~m}$. The second support takes advantage of steel pipe with an outer diameter is $800 \mathrm{~mm}$ and the inner diameter is $768 \mathrm{~mm}$. The crown beam is $900 \mathrm{~mm}$ high and $1200 \mathrm{~mm}$ wide. The foundation pit of this project is relatively wide, and a neutral column needs to be installed. Pillars are also set in the foundation pit. Through the project site exploration report, to facilitate quick modeling and calculation, the soils with similar properties are merged, the rock and soil layers are divided into three layers, and the Mohr-Coulomb constitutive model is used for calculation. In the modeling process, the properties of the soil are designed according to Table 1 , and the material parameters of the internal structure are shown in Table 2.

Table 1. Physical and mechanical parameters of the simplified stratum.

\begin{tabular}{|c|c|c|c|c|}
\hline Soil Layer Name & Thickness of Soil Layer (m) & Density $\left(\mathrm{g} / \mathrm{cm}^{3}\right)$ & Cohesion $(\mathrm{kPa})$ & Friction Angle $\left({ }^{\circ}\right)$ \\
\hline Miscellaneous fill & 4.90 & 1.88 & 10.00 & 8.00 \\
\hline Silt & 8.10 & 1.89 & 26.80 & 14.50 \\
\hline Silty clay & 27.10 & 1.92 & 34.80 & 16.30 \\
\hline
\end{tabular}

Table 2. Support structure parameters.

\begin{tabular}{cccc}
\hline & Geometric Properties & Density $\left(\mathrm{g} / \mathrm{cm}^{\mathbf{3}}\right)$ & Elastic Modulus $(\mathrm{GPa})$ \\
\hline Concrete support & $800 \mathrm{~mm} \times 800 \mathrm{~mm}$ & 2.4 & 30 \\
Steel support & $\mathrm{D}^{1}=600 \mathrm{~mm}$ or $800 \mathrm{~mm}$ & 7.8 & 210 \\
Diaphragm wall & $\mathrm{t}^{2}=16 \mathrm{~mm}$ & 2.4 & 30 \\
\hline
\end{tabular}

${ }^{1} \mathrm{D}$ represents the diameter of the steel pipe; ${ }^{2} \mathrm{t}$ represents the steel pipe thickness.

\subsection{Structural Unit Selection}

The soil layer is simulated by solid elements. Crown beams and reinforced concrete supports are simulated by beam elements, while steel supports are simulated by truss elements. The disjunction function in the diaphragm wall application software adopts a two-dimensional plate unit for simulation.

\subsection{Process Simulation of Construction}

In order to verify the correctness of the simulation results, the excavation steps were simplified into four stages (each stage lasts approximately 30 days), as shown in Table 3. The model result is shown in Figure 3. It is worth mentioning that the supporting structure corresponding to the excavated foundation pit is $0.5 \mathrm{~m}$ above the bottom of the pit in order to facilitate the construction of the excavator. 
Table 3. Simulated construction steps.

\begin{tabular}{ccc}
\hline Construction Condition & Supporting Structure & Excavation \\
\hline Step 1 & Activate the crown beam and first support & $\begin{array}{c}\text { Carry out the first excavation located at } \\
\text { 4.0 m below the surface }\end{array}$ \\
\hline Step 2 & Activate the second support & $\begin{array}{c}\text { Carry out the second excavation located } \\
\text { at } 8.1 \mathrm{~m} \text { below the surface }\end{array}$ \\
\hline Step 3 & Activate the third support & $\begin{array}{c}\text { Carry out the third excavation located at } \\
11.6 \mathrm{~m} \text { below the surface }\end{array}$ \\
\hline Step 4 & Activate the fourth support & $\begin{array}{c}\text { Carry out the fourth excavation located at } \\
18.0 \mathrm{~m} \text { below the surface }\end{array}$ \\
\hline
\end{tabular}

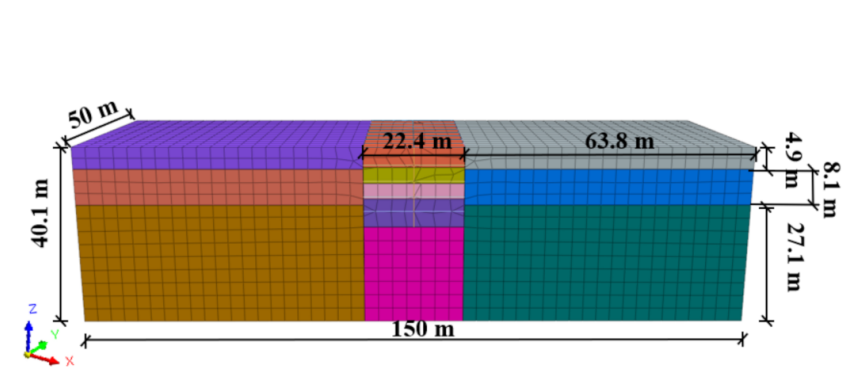

(a)

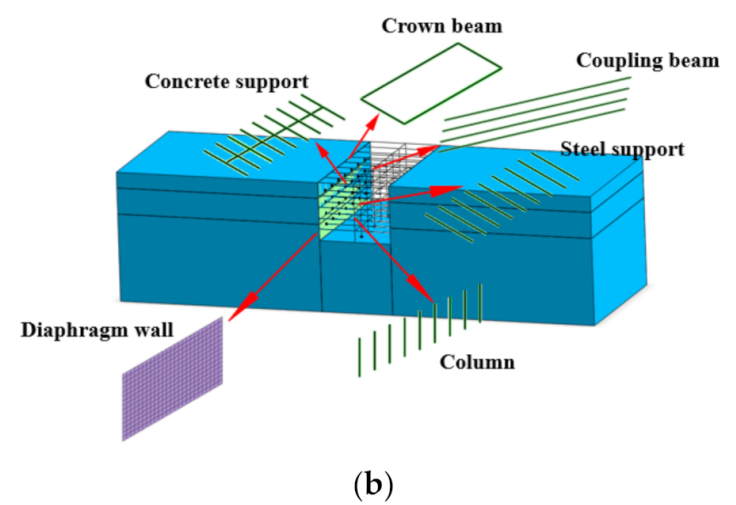

(b)

Figure 3. MIDAS/GTS numerical simulation diagram. (a) Foundation pit size. (b) Layout of foundation pit structure.

The purpose of this paper is to study the deformation of foundation pits using finite element analysis. More importantly, the models in this paper are symmetric, which leads to symmetry in results, such as in deformation distributions. The size of the foundation pit is consistent with the actual project, and in order to reduce the influence of boundary effects, the sizes of the models are more than double that of the foundation pit. As shown in Figure 3a, the length of the entire model is $150 \mathrm{~m}$, the width is $50 \mathrm{~m}$, and the height is $40.1 \mathrm{~m}$. The length of the foundation pit is $22.4 \mathrm{~m}$, the width is $50 \mathrm{~m}$, and the height is $18 \mathrm{~m}$. The internal support structure of the foundation pit is shown in Figure $3 \mathrm{~b}$. The excavation of the foundation pit is divided into four steps, and the distance from the bottom of the foundation pit to the surface of each excavation is shown in Figure 4.
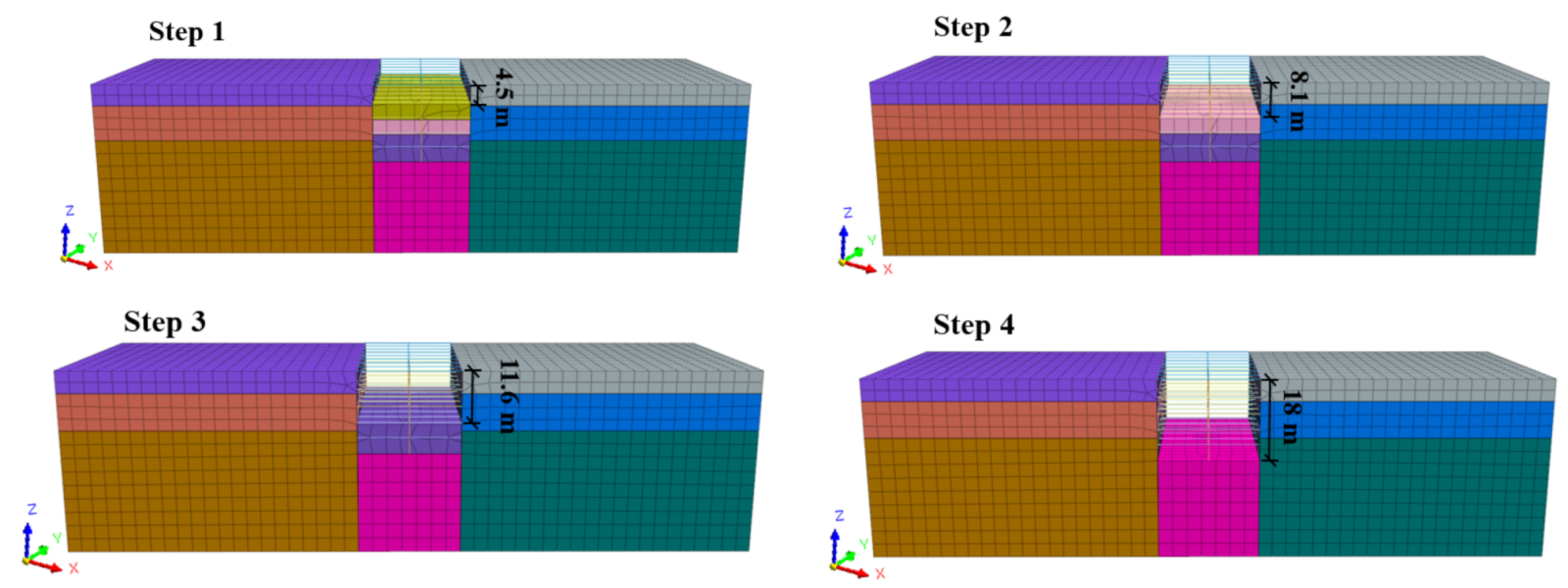

Figure 4. Foundation pit excavation steps. 


\section{Results and Discussion}

\subsection{Simulation Reliability Verification}

\subsubsection{Ground Settlement}

Due to the complexity of the engineering environment, the control of surface settlement during the excavation of foundation pits is focused on. Under the combined effect of multiple influencing factors, the stratum surrounding the foundation pit will eventually appear as settlement or uplift in the vertical direction, which affects the safety and stability of nearby underground pipelines or buildings (structures). Therefore, foundation pit surface settlement is carried out. Analysis and research in this area have important practical significance.

The ground loss is caused by the excavation of the foundation pit, leading to the surface deformation. The magnitude of surface deformation has a significant relationship with the distance from the edge of the foundation pit, as shown in Figure 4. The sedimentation trend in the $0-4 \mathrm{~m}$ section is relatively obvious, and the curve is relatively steep, while the curve in the 4-22 m section gradually rises, and the sedimentation trend becomes steady at 22-60 m. From the analysis in Figure 5, it can be seen that the maximum settlement of step 4 increased from $8.37 \mathrm{~mm}$ in step 1 to $21.23 \mathrm{~mm}$. The ratios of the maximum settlement of the four working conditions to the corresponding excavation depth are $0.19 \%, 0.13 \%$, $0.11 \%$, and $0.12 \%$. The maximum settlement position also extends from the position near the side of the pit to $4.87 \mathrm{~m}$ outside the pit.

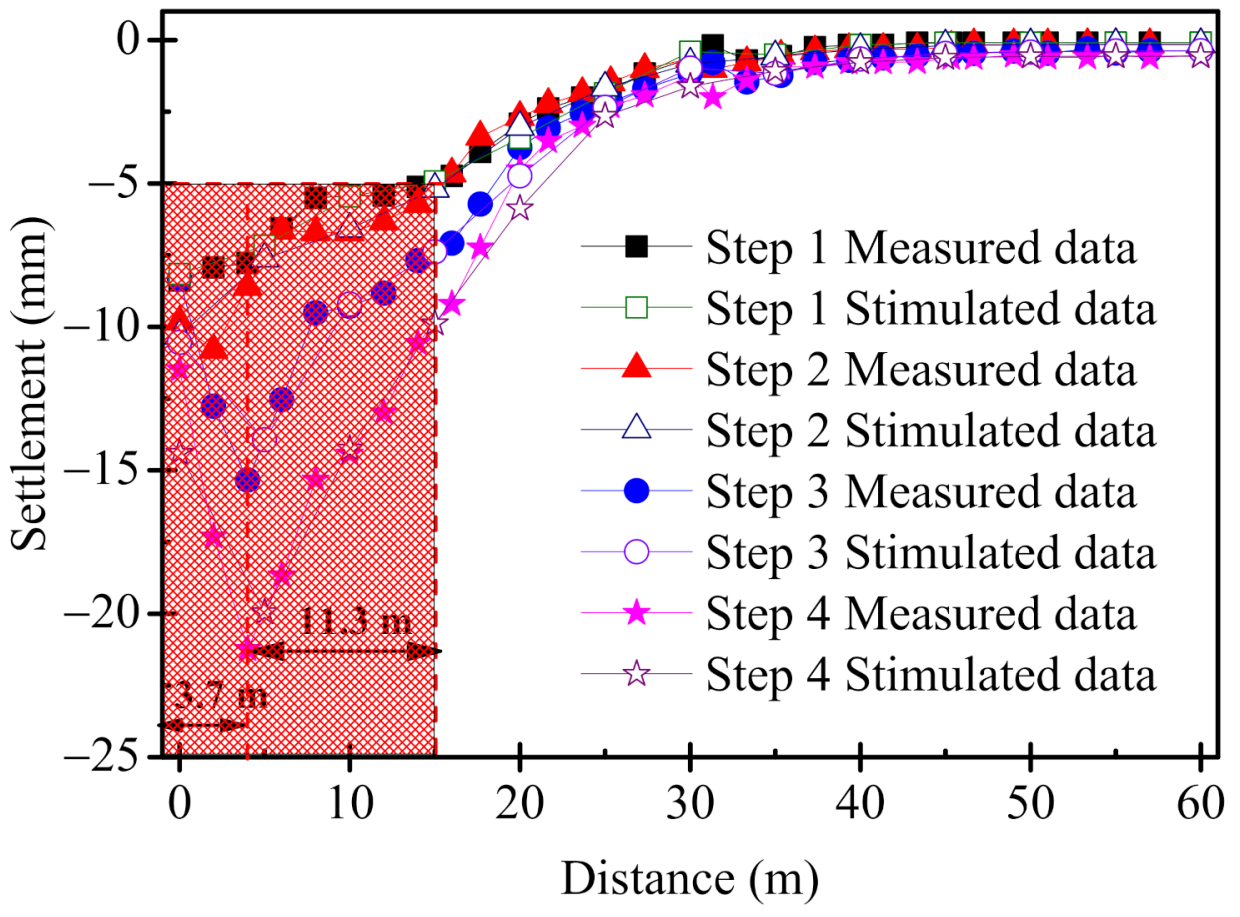

Figure 5. Ground settlement obtained by monitoring and simulation.

\subsubsection{Horizontal Displacement of Diaphragm Wall}

The deformation behavior of underground diaphragm walls and their influence have been extensively studied, and the laws of soil pressure distribution, building deformation, and ground subsidence have been obtained. However, engineering and academic circles are generally concerned about the ground settlement outside the pit and the water barrier effect of the diaphragm wall, the horizontal displacement of which has not received enough attention.

In Figure 6, the measured data of the diaphragm wall proves that the simulation results are reliable. By comparing the simulation results with the measured data, it can be seen that the maximum horizontal displacement of the diaphragm wall first increases 
and then decreases, as the depth of the diaphragm wall increases. Figure 6 shows that the side shift of working condition 4 reaches the maximum at a position of $10 \mathrm{~m}$, and the maximum horizontal displacement is $27 \mathrm{~mm}$. The curves show an inverted convex shape in the middle and the two sides, and the maximum displacement is approximately $8-10 \mathrm{~m}$ in the pit. This is because soil pressure has changed during the excavation of the pit. The initial soil pressure inside the foundation pit is eliminated, all or part of the passive soil pressure acts on the bottom wall of the pit, and the outside of the pit also bears the influence of the active soil pressure. After the pit floor is poured, the factors affecting the soil pressure on both sides of the diaphragm wall basically no longer change, and the displacement tends to be stable.

\section{Deformation ( $\mathrm{mm}$ )}

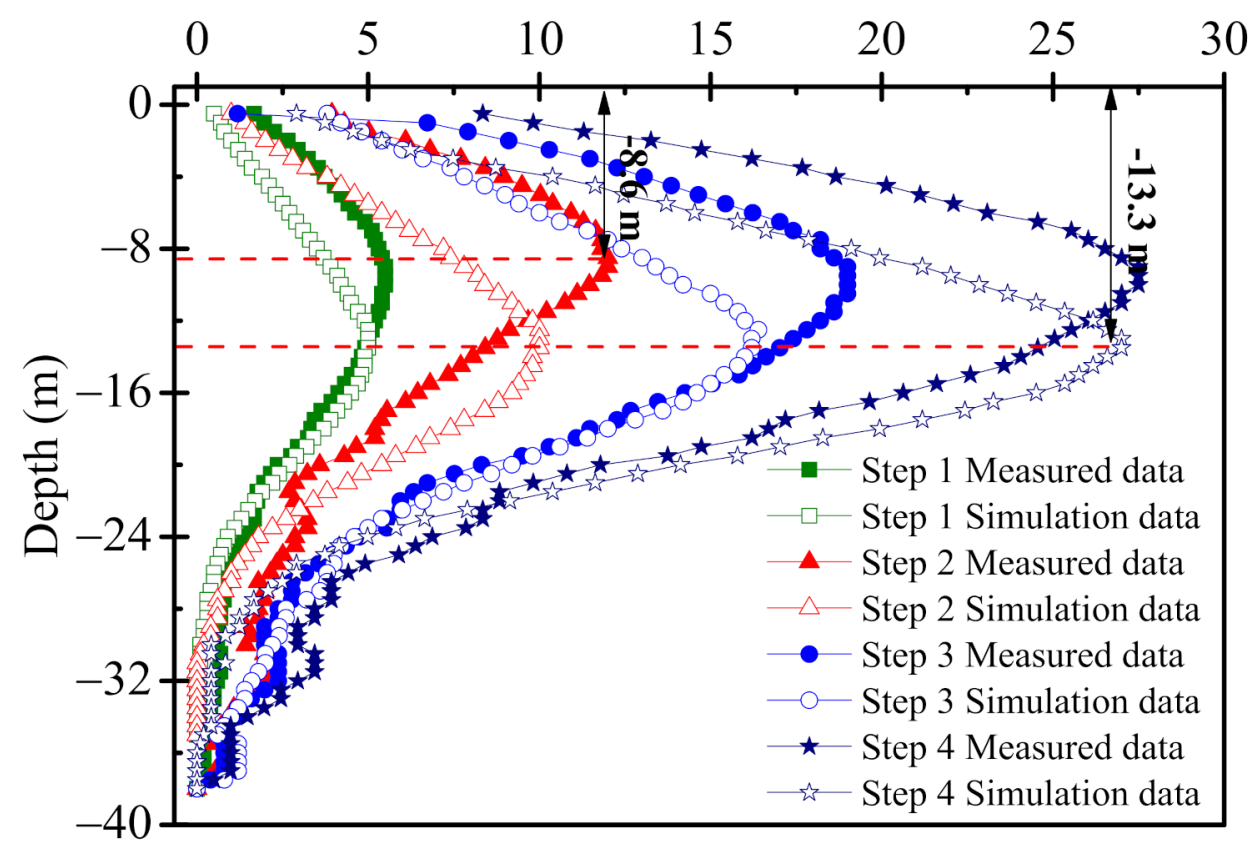

Figure 6. Horizontal displacement of the diaphragm wall obtained by monitoring and simulation.

\subsubsection{Crown Beam Displacement}

The displacements of the crown beam are important indicators for investigating the safety status of the supporting structure, as shown in Figure 7a. For the vertical deformation of the crown beam, the main influencing factors are the uplift of the foundation pit and the vertical load acting on it. As the vertical deformation of the crown beam sinks as a whole, it shows that the vertical load plays a key effect in the change of the vertical displacement of the crown beam. Due to the limited space of the construction site, a large amount of building materials piled around the foundation pit are the main source of the load. In Figure 6, the horizontal deformation of the crown beam has a small increasing trend after the complete the excavation of the pit. This is mainly because the earth pressure around the crown beam changes with time due to soil unloading and precipitation.

Comparing the simulation results with the measured results, it is known that the vertical displacement of the crown beam is close, as shown in Figure $7 \mathrm{~b}$. However, the simulated horizontal displacement is very different from the measured value. This is because, during the simulation process, a node coupling is formed between the diaphragm wall and the crown beam, the horizontal deformation of which is limited by the diaphragm wall. Therefore, the diaphragm wall near the ground restricts the horizontal displacement of the top beam, resulting in the simulated value of the crown beam being much lower than the measured data. 


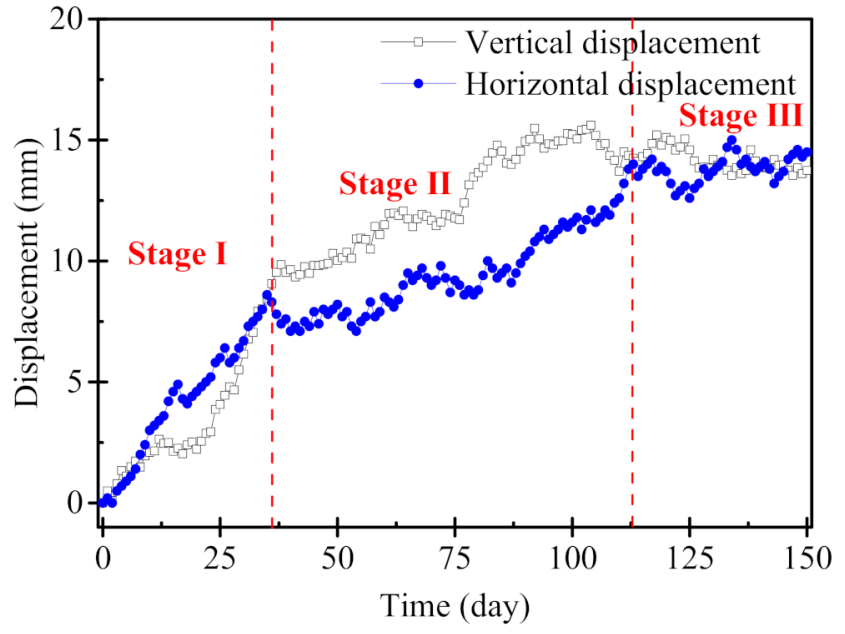

(a)

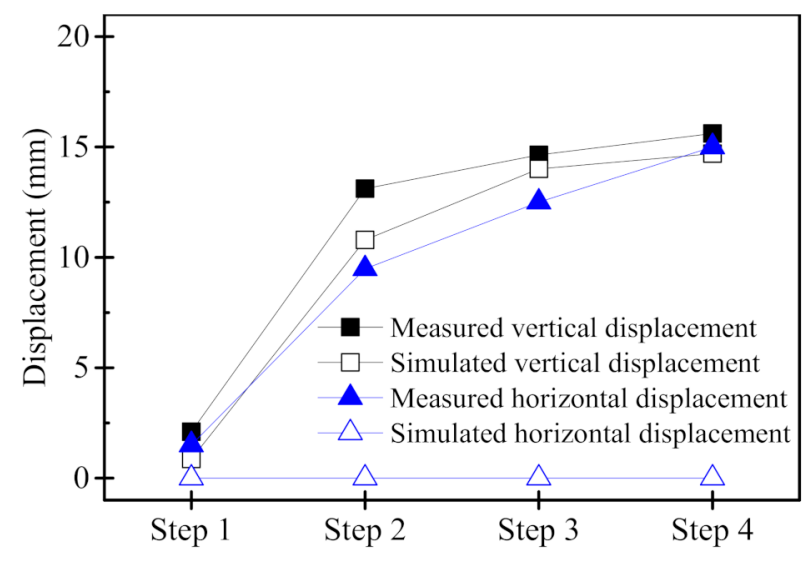

(b)

Figure 7. Horizontal and vertical displacement of the crown beam obtained by monitoring and simulation. (a) Horizontal and vertical displacement of the crown beam with time obtained by monitoring. (b) Horizontal and vertical displacement of the crown beam during different construction steps obtained by monitoring and simulation.

\subsubsection{Column Settlement}

For foundation pits with a large area and deep excavation depth, it is very important to monitor the settlement of the column during excavation. By monitoring the elevation change at the top of the column, the differential settlement of the column during the construction phase can be obtained. According to the differential settlement of the pillars, necessary remedial measures should be taken in time to avoid problems in the quality of the project.

Figure 8a shows the differential settlement of the monitored column. The results show that the differential settlement velocity of the column is faster between $28 \mathrm{~d}$ and $110 \mathrm{~d}$. Figure $8 \mathrm{~b}$ shows the variation curve of the differential settlement of the column under different construction stages. The column displacement is $21.5 \mathrm{~mm}$, which agrees well with the monitored value. Generally, the simulation data calculated by the Mohr-Coulomb model is slightly larger than the measured data. This is because in actual engineering, the soil reinforcement at the bottom of the pit and the cement mixing piles that prevent the soil from seeping outside the pit limit the displacement of the soil, which can reduce the pressure from the soil and strengthen the protection of the foundation pit. The calculation model failed to fully consider the restriction of soil reinforcement and other factors, which caused the numerical simulation results of the column uplift to be slightly larger than the measured results.

\subsection{Sensitivity Analysis}

This paper mainly studies the influence of the diaphragm wall insertion ratio and the soil parameters (elastic modulus, internal friction angle, and cohesion) on the maximum horizontal deformation of the diaphragm wall and the maximum ground settlement. The research results of this paper provide soil and diaphragm wall displacement laws for the construction of foundation pit engineering in the soft soil area of lakeside facies, as shown in Figure 9. Unless otherwise specified, the parameter selection of the numerical simulation follows Table 1 . This paper uses a single factor analysis method, only changing the influencing factors of a single study, and other factors remain unchanged. 


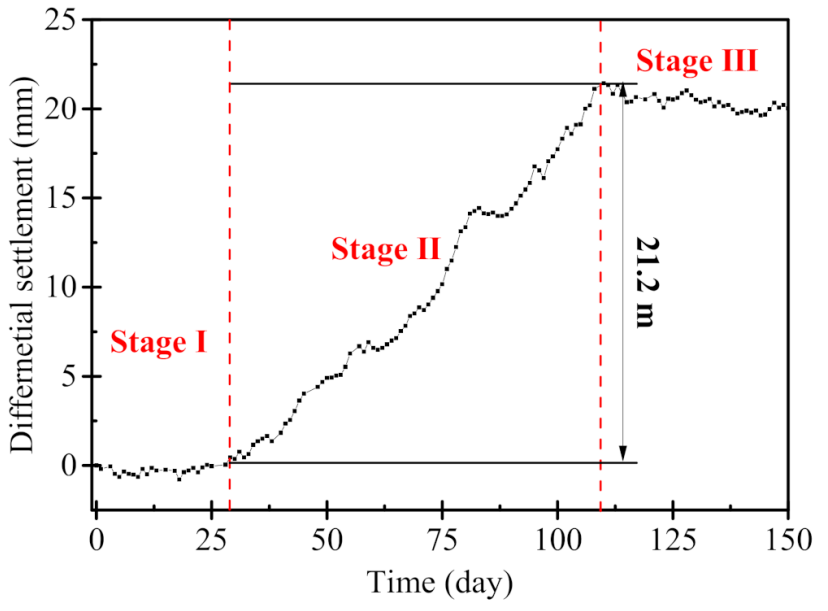

(a)

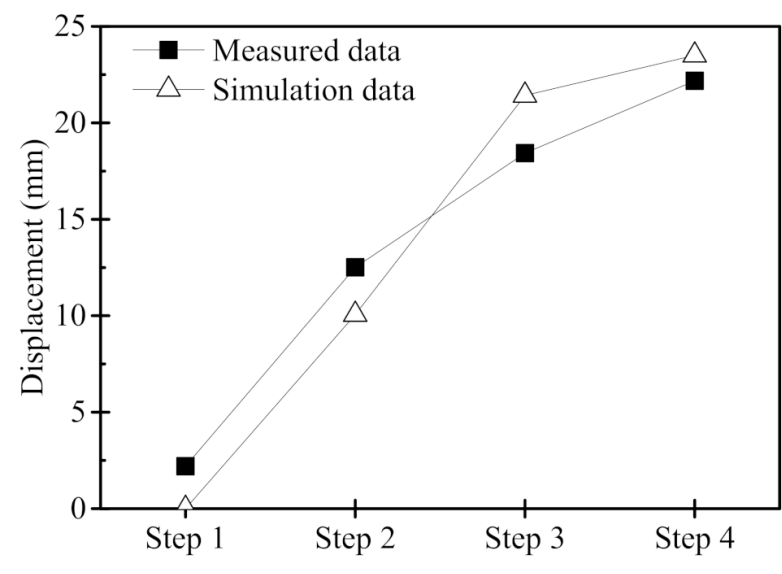

(b)

Figure 8. Differential settlement of the column obtained by monitoring and simulation. (a) Differential settlement of the column with time obtained by monitoring. (b) Differential settlement of the column during different construction steps obtained by monitoring and simulation.

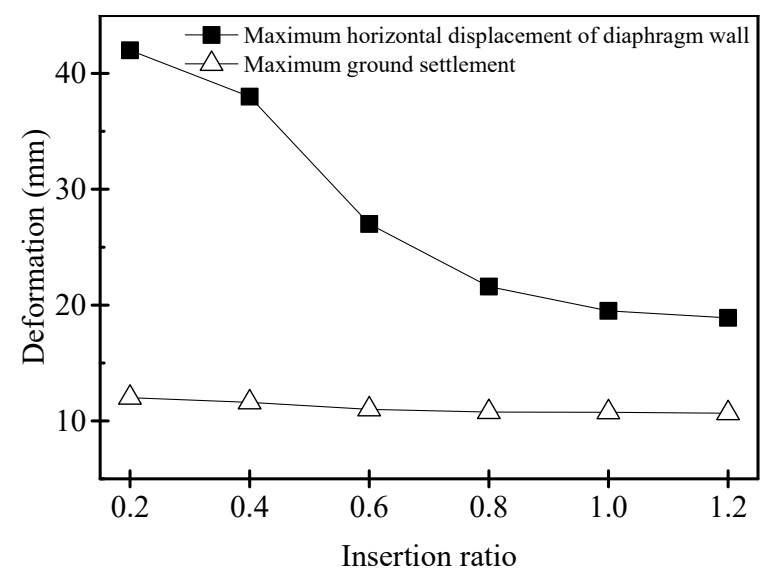

(a)

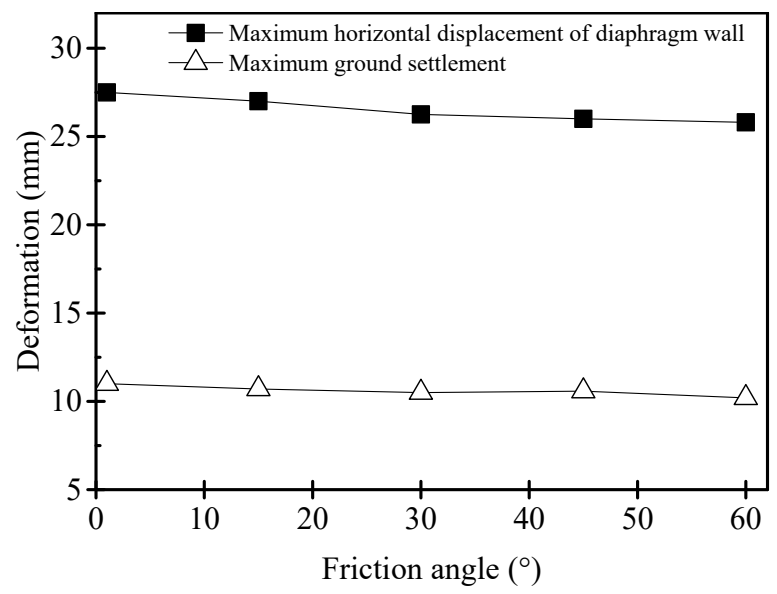

(c)

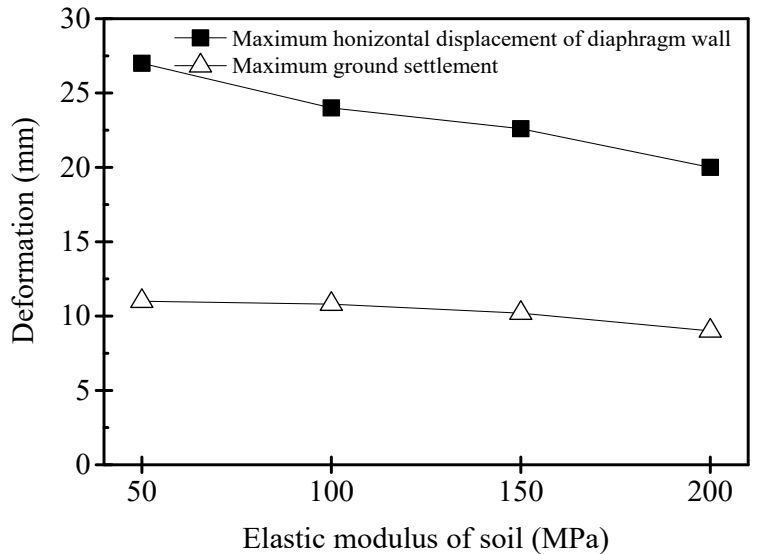

(b)

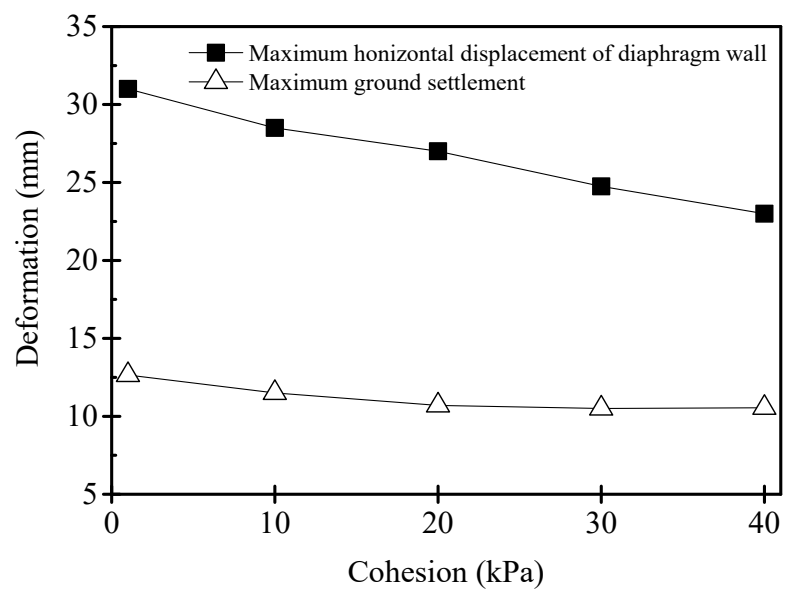

(d)

Figure 9. Maximum ground settlement and maximum horizontal displacement of the diaphragm wall under different conditions. (a) Insertion ratio of diaphragm wall. (b) Elastic modulus of soil. (c) Friction angle of soil. (d) Cohesion of soil. 


\subsubsection{Insertion Ratio of Diaphragm Wall}

The diaphragm wall is an important part of the foundation pit enclosure system, which can resist the earth pressure caused by the imbalance of the soil. Therefore, the design of the embedding depth of the diaphragm wall is very important. If the embedding depth is insufficient, it may cause instability of the pit, and if the embedding depth wall is too large, the construction cost will be greatly increased. The insertion ratio of the diaphragm wall refers to the ratio of the height below the pit of the diaphragm wall to the excavation depth of the pit of the diaphragm wall. The numerical simulation calculation changes the insertion ratio by adjusting the depth of the diaphragm wall into the soil.

Figure 9a shows that the maximum horizontal morph value of the diaphragm wall decreases with the increasing of the insertion ratio. The sensitivity of the maximum horizontal displacement of the diaphragm wall is more affected by the insertion ratio of the diaphragm wall than other factors. As the insertion ratio is larger, the embedding depth of the underground diaphragm wall also increases, resulting in an increase in construction costs. It is most reasonable when the integrated value is 0.6. In Figure 6, when the insertion ratio $\lambda$ of the underground diaphragm wall increases from 0.2 to 1.2 , the surface settlement value continues to decrease. However, the maximum settlement value only decreases from $12 \mathrm{~mm}$ to $10.66 \mathrm{~mm}$, revealing the contrast in the insertion ratio of the underground diaphragm wall as compared to that of the pit.

\subsubsection{Elastic Modulus of Soil}

Figure $9 \mathrm{~b}$ shows that as the elastic modulus increases, the lateral deformation of the continuous wall decreases. When the elastic modulus increases from $50 \mathrm{MPa}$ to $200 \mathrm{MPa}$, the maximum horizontal morph of the continuous wall is reduced by $35 \%$. To analyze the change law of the foundation pit's bottom settlement under different elastic modulus, the largest ground settlement value in each model is, at this stage, extracted, as shown in Figure $9 \mathrm{~b}$. Furthermore, the maximum ground settlement decreases with the increasing of the elastic modulus.

\subsubsection{Internal Friction Angle}

Figure $9 \mathrm{c}$ shows the horizontal morph comparison curve of the diaphragm wall when the friction angle in the soil body changes. It can be seen from the figure that the horizontal morph of the diaphragm wall decreases as the friction angle inside the soil increases. With the increasing of the friction angle in the soil body, the horizontal morph of the diaphragm wall and the maximum ground settlement both decrease. When the internal friction angle is increased from $1^{\circ}$ to $60^{\circ}$, the horizontal morph of the diaphragm wall is reduced by $6 \%$ and the maximum ground settlement drops by $0.8 \mathrm{~mm}$.

\subsubsection{Cohesion of Soil}

In this paper, numerical simulation methods are used to customize the cohesion of the soil. Figure $9 \mathrm{~d}$ shows that the lateral deformation of the underground diaphragm wall decreases with the increasing of the cohesion, which basically shows a linear relationship. With the cohesive force increasing from $1 \mathrm{kPa}$ to $40 \mathrm{kPa}$, the horizontal morph of the diaphragm wall is decreased by $28 \%$. This is mainly because as the soil cohesion increases, the self-stabilization height of the foundation pit during excavation also increases. In addition, the maximum ground settlement decreases with the increasing of the cohesion. When the cohesive force is increased from $1 \mathrm{kPa}$ to $40 \mathrm{kPa}$, the maximum ground settlement decreases by $2.4 \mathrm{~mm}$.

\subsection{Discussion}

The above research shows that the excavation depth plays an important role in terms of affecting the ground settlement and supporting structure. The maximum surface settlement and the maximum horizontal deformation of the diaphragm wall constitute an important basis for the study of stratigraphic effects and the reasonable optimization of 
construction parameters. Therefore, based on the summary of previous studies [35-38], this paper compares and analyzes the maximum ground subsidence and maximum horizontal deformation of the diaphragm wall. This is of great significance for both on-site construction risk control and future design optimization and improvements.

The maximum surface settlement increases as the depth of the pit increases, as shown in Figure 10. The maximum ground settlement of the foundation pit is $0.313 \% \mathrm{D}_{\max }$ and the minimum is $0.06 \% \mathrm{D}_{\max }$. The maximum settlement $\left(0.15 \mathrm{D}_{\max }\right)$ in this paper is between the statistical values. In this paper, the maximum ground subsidence is $0.144 \% \mathrm{D}_{\text {max }}$, which indicates that the deformation of the soft clay is too large relative to the sand and pebble foundation due to its weak bearing capacity.

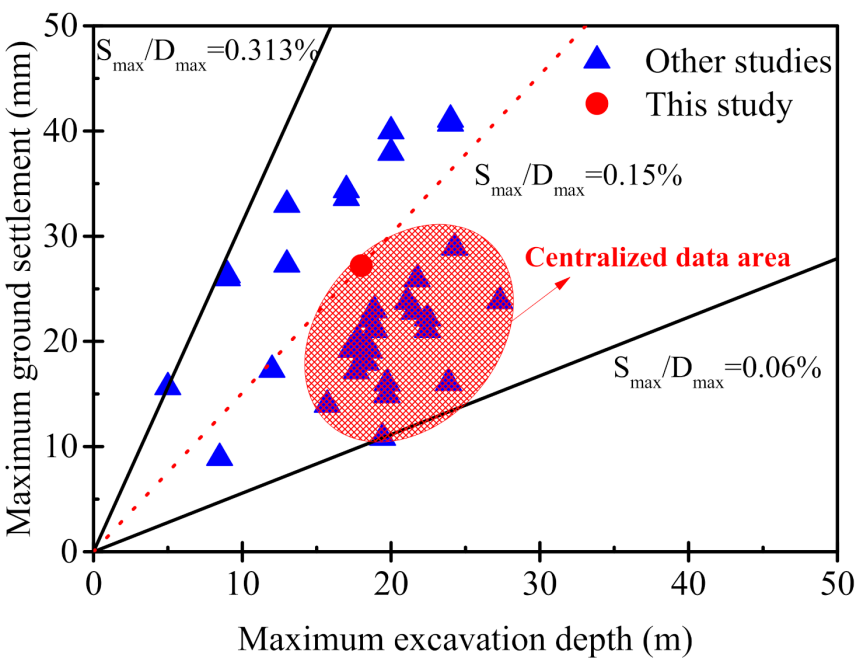

Figure 10. Maximum ground settlement at maximum excavation depth.

This paragraph reveals the influence of the excavation depth of the foundation pit according to the maximum deformation of different enclosure structures. The relationship between the maximum horizontal displacement of the supporting structure and the maximum excavation depth is shown in Figure 11. Through comparison with other research results, the ratio of the maximum deformation of the supporting structure to the maximum excavation depth $\left(\mathrm{H}_{\max } / \mathrm{D}_{\max }\right)$ is limited to a certain range between $0.07 \%$ and $0.25 \%$. In this paper, the ratio of the displacement of the retaining structure to the excavation depth is 0.16 , which conforms to the general law.

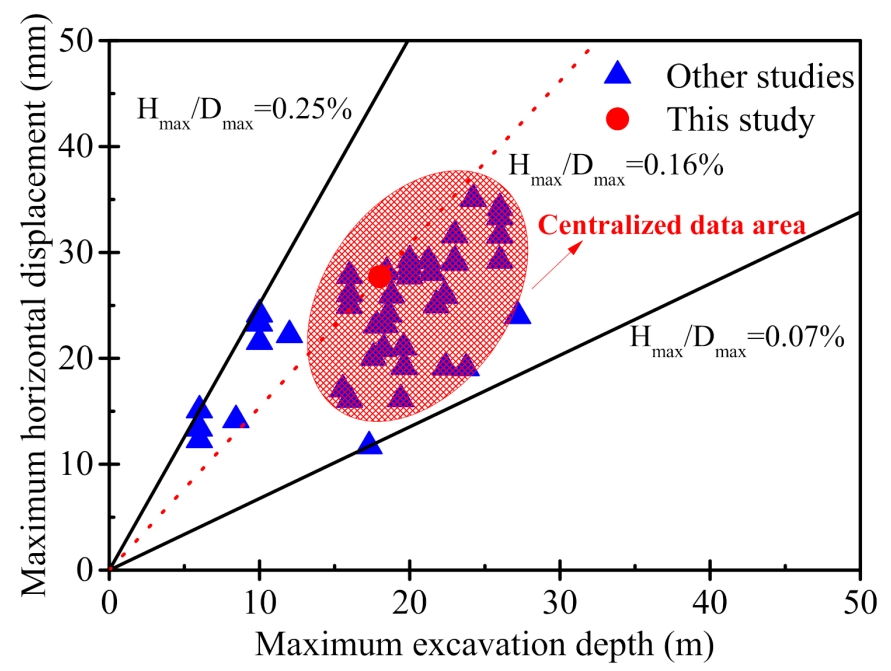

Figure 11. Maximum horizontal displacement of the retaining structure at the maximum excavation depth. 


\section{Conclusions}

This paper studies the deformation characteristics of the surroundings and structure of the foundation pit, based on the excavation of a certain foundation pit, combined with the results of numerical analysis. The conclusions are as follows:

1. Numerical calculations using MIDAS can fit the measured data well. This paper provides experience for similar future projects related to the study of the support structure, the surface settlement around the foundation pit, and the resistance to the uplift at the bottom of the foundation pit. With the continuous excavation of the foundation pit, the maximum horizontal displacement and maximum land subsidence of the underground diaphragm wall also increase. After the foundation pit's excavation is completed, the maximum horizontal displacement of the underground diaphragm wall is $9.45 \mathrm{~mm}$, and the maximum surface settlement is $21.25 \mathrm{~mm}$. The displacement of the crown beam is divided into three stages; the first stage's displacement exceeds $75 \%$ of the total displacement. The uplift at the bottom of the foundation pit is reflected by the deformation of the column, and the largest pit bottom uplift is $21.46 \mathrm{~mm}$.

2. Considering the elastic modulus, cohesion, internal friction angle, and insertion ratio of the diaphragm wall, the sensitivity analysis is conducted based on the maximum settlement of the diaphragm wall and the surface. This paper comprehensively considers the cost and risk, and provides an idea for selecting the optimal insertion ratio for the foundation pit of the underground diaphragm wall as the supporting structure. The cohesion, internal friction angle, elastic modulus, and insertion ratio have negative effects on the deformation of foundation pits and diaphragm walls. Among them, the effects of the insertion ratio and elastic modulus, in terms of limiting the maximum displacement of the foundation pit and the diaphragm wall, are better than the effects of the cohesion and internal friction angle.

3. Summarizing the research results of other scholars, the maximum land subsidence and maximum horizontal displacement of the supporting structure are positively correlated with the excavation depth. The ratio of the maximum surface settlement to the maximum excavation depth is $0.313-0.060 \%$, and the ratio of the maximum horizontal displacement of the support structure to the maximum excavation depth is $0.07-0.25 \%$. The research results summarized in this paper can be used as a means to assess the control risk of foundation pit excavation.

Author Contributions: Conceptualization, X.X. and Q.T.; Methodology, writing-original draft, Z.F.; Investigation, software, Q.X.; Validation, formal analysis, writing-review and editing, X.X.; Supervision, Q.T., X.L. (Xuedong Li) and X.L. (Xin Liao). All authors have read and agreed to the published version of the manuscript.

Funding: The research presented here is supported by the National Natural Science Foundation of China (52078317), the Natural Science Foundation of Jiangsu Province for Excellent Young Scholars (BK20211597), projects of the Bureau of Housing and Urban-Rural Development of Suzhou (2021-25; 2021ZD02; 2021ZD30), the Bureau of Geology and Mineral Exploration of Jiangsu (2021KY06), China Tiesiju Civil Engineering Group (2021-19), the CCCC First Highway Engineering Group Company Limited (KJYF-2021-B-19), and the CCCC Tunnel Engineering Company Limited (8gs-2021-04).

Institutional Review Board Statement: Not applicable.

Informed Consent Statement: Not applicable.

Data Availability Statement: The data presented in this study are available on request from the corresponding author.

Conflicts of Interest: The authors declare no conflict of interest. 


\section{References}

1. Nguyen, T.S.; Likitlersuang, S. Reliability analysis of unsaturated soil slope stability under infiltration considering hydraulic and shear strength parameters. Bull. Eng. Geol. Environ. 2019, 78, 5727-5743. [CrossRef]

2. Lin, H.-D.; Wang, W.-C.; Li, A.-J. Investigation of dilatancy angle effects on slope stability using the 3D finite element method strength reduction technique. Comput. Geotech. 2020, 118, 103295. [CrossRef]

3. VandenBerge, D.R.; McGuire, M.P. Practical Use of Modified Hoek-Brown Criterion for Soil Slope Stability Analysis. Geotech. Geol. Eng. 2019, 37, 5441-5455. [CrossRef]

4. Moormann, C. Analysis of Wall and Ground Movements Due to Deep Excavations in Soft Soil Based on a New Worldwide Database. Soils Found. 2004, 44, 87-98. [CrossRef]

5. Wang, Z.W.; Ng, C.W.; Liu, G.B. Characteristics of wall deflections and ground surface settlements in Shanghai. Can. Geotech. J. 2005, 42, 1243-1254. [CrossRef]

6. Kalatehjari, R.; Ali, N.M.M.; Kholghifard, M.; Hajihassani, M. The effects of method of generating circular slip surfaces on determining the critical slip surface by particle swarm optimization. Arab. J. Geosci. 2013, 7, 1529-1539. [CrossRef]

7. Sedighi, H.M.; Bozorgmehri, A. Nonlinear vibration and adhesion instability of Casimir-induced nonlocal nanowires with the consideration of surface energy. J. Braz. Soc. Mech. Sci. Eng. 2017, 39, 427-442. [CrossRef]

8. Lancellotta, R. Analytical solution of passive earth pressure. Géotechnique 2002, 52, 617-619. [CrossRef]

9. Greco, V.R. Discussion of "Seismic active earth pressure behind a nonvertical retaining wall using pseudo-dynamic analysis". Can. Geotech. J. 2008, 45, 1795-1797. [CrossRef]

10. Gnanapragasam, N. Active earth pressure in cohesive soils with an inclined ground surface. Can. Geotech. J. 2000, 37, 171-177. [CrossRef]

11. Xiang, G.J.; Yin, D. Application of artificial neural network for prediction of flow ability of soft soil subjected to vibrations. Geomech. Eng. 2021, 25, 395-403. [CrossRef]

12. Das, A.K.; Deb, K. Response of Cylindrical Storage Tank Foundation Resting on Tensionless Stone Column-Improved Soil. Int. J. Geomech. 2017, 17, 04016035. [CrossRef]

13. Zheng, G.; Yang, X.; Zhou, H.; Chai, J. Numerical modeling of progressive failure of rigid piles under embankment load. Can. Geotech. J. 2019, 56, 23-34. [CrossRef]

14. Gnanendran, C.T.; Manivannan, G.; Lo, S.-C. Influence of using a creep, rate, or an elastoplastic model for predicting the behaviour of embankments on soft soils. Can. Geotech. J. 2006, 43, 134-154. [CrossRef]

15. Zhang, L.; Wang, J.; Hu, X.; Zhou, J.; Zhao, M.; Zhang, J.; Bo, Y.; Huang, Y.; Zhang, Y. VOCs and PM concentrations in underground parking garages of the commercial center and high-rise residential buildings. Air Qual. Atmos. Health 2021, 14, 1117-1131. [CrossRef]

16. Sun, H.; Chen, Y.; Zhang, J.; Kuang, T. Analytical investigation of tunnel deformation caused by circular foundation pit excavation. Comput. Geotech. 2019, 106, 193-198. [CrossRef]

17. Liu, L.; Wu, R.; Congress, S.S.C.; Du, Q.; Cai, G.; Li, Z. Design optimization of the soil nail wall-retaining pile-anchor cable supporting system in a large-scale deep foundation pit. Acta Geotech. 2021, 16, 2251-2274. [CrossRef]

18. Zhang, J.; Li, M.; Ke, L.; Yi, J. Distributions of lateral earth pressure behind rock-socketed circular diaphragm walls considering radial deflection. Comput. Geotech. 2021, 143, 104604. [CrossRef]

19. Zhu, C.; Yan, Z.; Lin, Y.; Xiong, F.; Tao, Z. Design and Application of a Monitoring System for a Deep Railway Foundation Pit Project. IEEE Access 2019, 7, 107591-107601. [CrossRef]

20. Sun, Y.; Xiao, H. Wall Displacement and Ground-Surface Settlement Caused by Pit-in-Pit Foundation Pit in Soft Clays. KSCE J. Civ. Eng. 2021, 25, 1262-1275. [CrossRef]

21. Zhao, Z.; Zhu, Y.; Ye, S. Study on settlement deformation of high fill foundation in large thickness loess area. Arab. J. Geosci. 2021, 14, 1-12. [CrossRef]

22. Finno, R.J.; Blackburn, J.T.; Roboski, J.F. Three-Dimensional Effects for Supported Excavations in Clay. J. Geotech. Geoenviron. Eng. 2007, 133, 30-36. [CrossRef]

23. Lin, P.; Liu, P.; Ankit, G.; Singh, Y.J. Deformation Monitoring Analysis and Numerical Simulation in a Deep Foundation Pit. Soil Mech. Found. Eng. 2021, 58, 56-62. [CrossRef]

24. Liang, J.J.; Wang, F.; Liu, Y.W.; Sun, X.Y. The Numerical Simulation and Deformation Analysis to the Deep Foundation Pit of Diaphragm Wall Based on Midas/GTS. Appl. Mech. Mater. 2015, 733, 456-459. [CrossRef]

25. Wang, Z. Numerical Analysis of Deformation Control of Deep Foundation Pit in Ulanqab City. Geotech. Geol. Eng. 2021, 39, 5325-5337. [CrossRef]

26. Li, W.; Fu, L.; Zhu, Z. Numerical simulation and land subsidence control for deep foundation pit dewatering of Longyang Road Station on Shanghai Metro Line 18. J. Groundw. Sci. Eng. 2019, 7, 133-144.

27. Liu, Y.L. Numerical Analysis of the Deformation Law of Deep Foundation Pit of Subway Station by FLAC3D. Adv. Mater. Res. 2014, 915, 62-67. [CrossRef]

28. Cui, X.; Ye, M.; Zhuang, Y. Performance of a foundation pit supported by bored piles and steel struts: A case study. Soils Found. 2018, 58, 1016-1027. [CrossRef]

29. Liu, S.; Li, H.; Tong, L. Simulation of pile cap contribution to the lateral pile performance due to adjacent excavation. Acta Geotech 2021, 16, 1895-1907. [CrossRef] 
30. Bai, J.; Chen, H.; Jia, J.; Sun, B.; Jin, S. New lateral load distribution pattern for seismic design of deteriorating shear buildings considering soil-structure interaction. Soil Dyn. Earthq. Eng. 2020, 139, 106344. [CrossRef]

31. Buchholtz, E.A.; Yozgyur, Z.M.; Feldman, A.; Weaver, A.A.; Gaudin, T.J. The therian sternum at the lateral somitic frontier: Evolution of a composite structure. J. Zool. 2021, 315, 19-28. [CrossRef]

32. Naseri, S.; Bahrani, N. Design of Initial Shotcrete Lining for a Mine Shaft Using Two-Dimensional Finite Element Models Considering Excavation Advance Rate. Geotech. Geol. Eng. 2021, 39, 4709-4732. [CrossRef]

33. Liu, X.; El Naggar, M.H.; Wang, K.; Tu, Y.; Qiu, X. Simplified model of defective pile-soil interaction considering three-dimensional effect and application to integrity testing. Comput. Geotech. 2021, 132, 103986. [CrossRef]

34. Kechidi, S.; Colaço, A.; Costa, P.A.; Castro, J.M.; Marques, M. Modelling of soil-structure interaction in OpenSees: A practical approach for performance-based seismic design. Structures 2021, 30, 75-88. [CrossRef]

35. Yang, T.L.; Yan, X.X.; Wang, H.M.; Huang, X.L.; Zhan, G.H. Comprehensive experimental study on prevention of land subsidence caused by dewatering in deep foundation pit with hanging waterproof curtain. Proc. Int. Assoc. Hydrol. Sci. 2015, 372, 1-5. [CrossRef]

36. Gerczuk, P.Z.; Kloner, R.A. An update on cardioprotection, a review of the latest adjunctive therapies to limit myocardial infarc-tion size in clinical trials. J. Am. Coll. Cardiol. 2012, 59, 969-978. [CrossRef] [PubMed]

37. Ding, Z.; Jin, J.; Han, T.-C. Analysis of the zoning excavation monitoring data of a narrow and deep foundation pit in a soft soil area. J. Geophys. Eng. 2018, 15, 1231-1241. [CrossRef]

38. Yang, J.; Kong, D. Deformation of deep and large foundation pit in soft soil of Fuzhou Subway. Arab. J. Geosci. 2020, 13, 1-10. [CrossRef] 